\title{
A NEW MODIFIED SYSTEM FOR EQUAL POWER DIVISION WITH LCC FOR WIRELESS APPLCATIONS
}

\author{
S.Banu ${ }^{1}$, A.Vishwapriya ${ }^{2}$, R.Yogamathi ${ }^{3}$, A.V.Meenakshi ${ }^{4}$, SPK.Babu $^{5}$ \\ Periyar maniyammai university, Thanjavur \\ rememberbanu@gmail.com, vishwaa.nivi@gmail.com, yoga.mathi@yahoo.com
}

\begin{abstract}
In this paper, a new modified system for equal power division is implemented with the help of rectangular micro strip patch antenna, Gysel power divider and leakage cancellation circuit. Today's world power division plays an important role in wireless application areas such as base stations, antenna arrays, handheld devices etc., Here micro strip patch antenna is implemented with FR4 as a substrate material due to its benefits such as low loss and low fabrication cost while the ground material is aluminium due to its conductivity. For a good system, the return loss should be highly desirable and insertion loss should be low. Our proposed system is designed with a combination of micro strip patch antenna, leakage cancellation circuit and Gysel power divider produces equal power division with low loss such as insertion loss is measured as $-39.291 \mathrm{~dB}$, return loss as $-16.11 \mathrm{~dB}$ and leakage cancellation as $6 \mathrm{~dB}$ which was designed and simulated in Agilent Advanced Design System software (2009).
\end{abstract}

\section{Keywords}

Advanced Design System software (2009) (ADS), Gysel Power Divider (GPD), Leakage Cancellation Circuit (LCC), Wilkinson Power Divider (WPD), Return Loss (RL), Insertion Loss (IL)

\section{INRODUCTION}

In today's world, wireless applications plays a major role especially in wireless communication systems. For this application there is a need of equal power division between the base station and the user with low loss and high signal strength. So, in this paper, we have introduced a new modified system for equal power division using GPD with low loss (in dB), LCC[10] circuit where as the presence of rectangular micro strip patch antenna [6] provides the input to the system. Section 1.1 deals about GPD where as section 1.2 says about LCC and section 1.3 deals about rectangular micro strip patch antenna. Section II deals about the implementation part while section III tells about simulation results and discussion. Section IV and V implies about conclusion and references respectively.

\subsection{GPD}

In general, power dividers are also called as power splitters, when used in reverse acts as the power combiner. It plays a vital role in various RF and communication applications $[1,2]$. The areas of applications are TV analyzer, hand-held spectrum analyzer, antenna arrays, and

DOI : $10.5121 /$ ijist.2012.2606 
microwave applications, WLAN such as $802.11 \mathrm{~b}, 802.11 \mathrm{~g}$, and $802.11 \mathrm{n}$ over a frequency range of $2.4 \mathrm{GHz}$ band. It is a passive device[4] which is used in the field of radio technology which requires power to be distributed among different paths. Power dividers are used especially for antenna array systems that utilize power-splitting network, such as a corporate or parallel feed system. The desirable properties of a power divider are low insertion loss, low isolation loss, high isolation between output ports and high return loss. The additional deseriable property of a power divider is wider bandwidth leading to number of sections and is helpful for $\mathrm{N}$-way power division $[1,2]$. As opposed to WPD[3], GPD is used to successfully combine and divide RF power above 10 kilowatt level for each input[5]. This design has characteristics such as low insertion loss, high isolation between output ports, matched conditions at all ports, external high power load resistors and monitoring capabilities for imbalances at the input ports. GPD[4] has not only the advantage of high power-handling capability [12] but also monitoring capability for imbalance at the output ports. In the above aspects it outperforms the WPD[3].

\section{$1.2 \mathrm{LCC}$}

The main advantage of this circuit is to improve the isolation between transmitter and receiver.

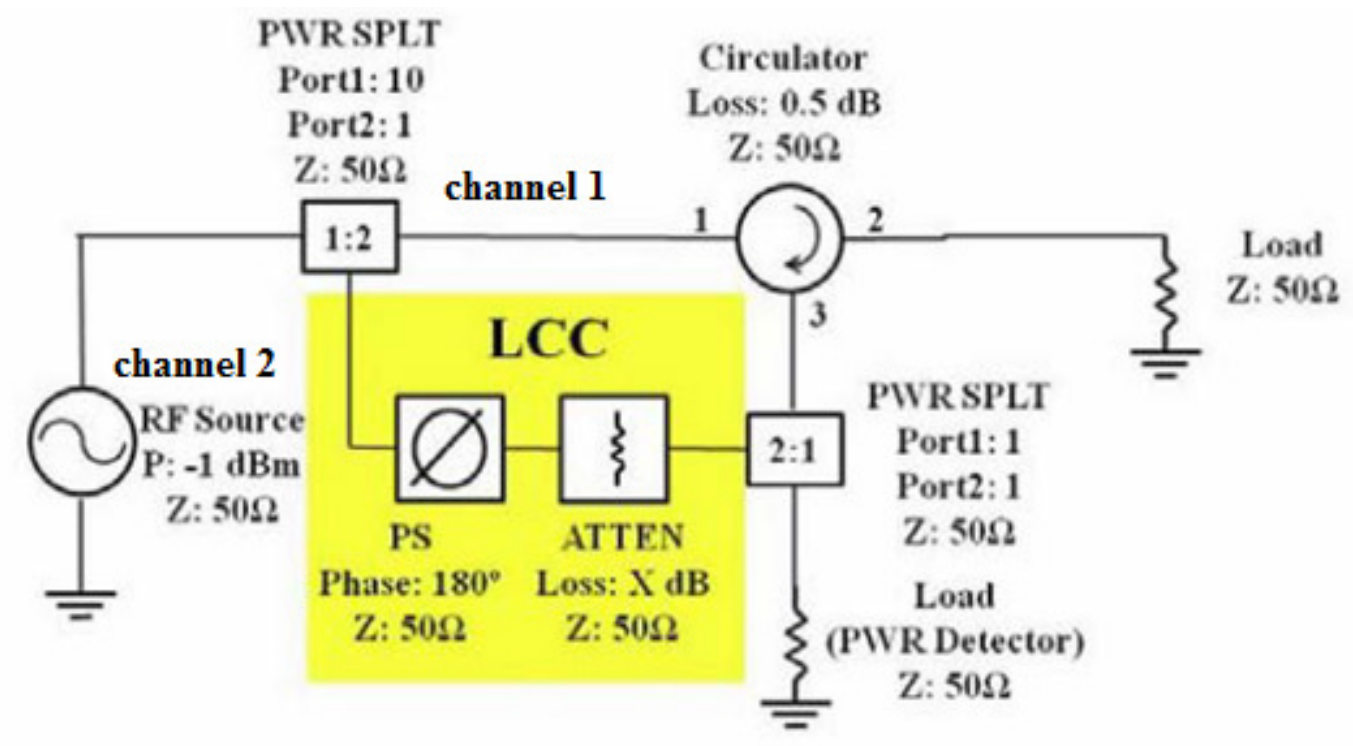

Figure 1: General representation of LCC[10]

From the above figure, LCC can be indicated by an attenuator and phase shifter[10]. While splitting the incoming power using power splitter, some amount of incoming power is circulated where as the other part of incoming power is given to LCC and the output is the cancellation signal (C) designed to cancel leakage signal $(L)$ from the circulator. The cancellation improvement in $\mathrm{dB}$ is given below,

$$
\mathrm{CI}=10 \log \left(\frac{\mathrm{R}}{\mathrm{L}+\mathrm{M}}\right)=10 \log \left(1-\frac{C}{L+M}\right)
$$


From the above description, LCC is comprised of both phase shifter and attenuator[10]. But generally there is some difficulties to match both the phase and amplitude of the leakage to achieve $\mathrm{R}=0$. When the signals from two channels are being added, the total voltage becomes

$$
\mathrm{V}=\mathrm{V}_{1}+\mathrm{V}_{2}=1+\alpha \varepsilon^{i \Phi}
$$

Where channel 1 is used as a reference $\left(\mathrm{V}_{1}=1\right)$ and $\alpha$ and $\Phi$ are the relative amplitude and phase of channel 2 to the reference. Thus, the amplitude imbalance is simply $\alpha$ and the phase imbalance is $\Phi . \quad \mathrm{V}_{2}$ represents the cancellation voltage $\mathrm{C}$. The main aim of the cancellation branch is to cancel the leakage $\mathrm{L}$ and mismatch $\mathrm{M}$ which implies only the desired signal $\mathrm{S}$ [10].

\subsection{Rectangular Microstrip Patch Antenna}

There are many types of antenna with each one has their own characteristics[6]. But here we used a micro strip patch antenna which radiates primarily because of the fringing fields between the patch edge and the ground plane. Due to its low profile structure it became popular one to use in wireless applications, satellite applications and military applications. It realizes the good antenna parameters such as high efficiency, low dielectric constant, small size and good radiation pattern. We implement micro strip patch antenna in our system due to its advantages such as light weight, low volume, supports both linear as well as circular polarization, capable of dual and triple frequency operations and low fabrication cost[6].

\section{PROPOSED SYSTEM MODEL}

From the above section, GPD leads to equal power division with high power handling capabilities. In the existing system, GPD has been used as a combiner rather than divider in TV applications because of its high isolation between the ports. But in our system, we implement such a GPD with LCC[6] and micro strip patch antenna. Here the system receive the power source from the micro strip patch antenna and then the leakage cancellation circuit cancels the leakage and give the source to power divider to provide equal power division which can be applicable to TV applications, broad cast applications and base stations.

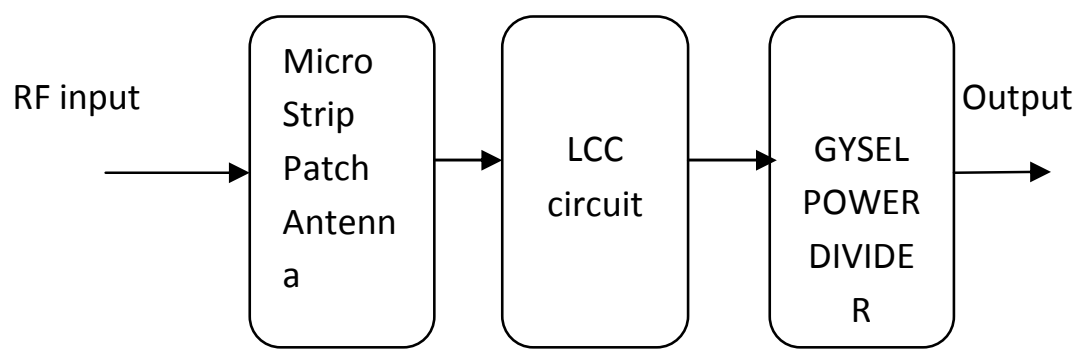

Figure3: Block diagram of proposed system 


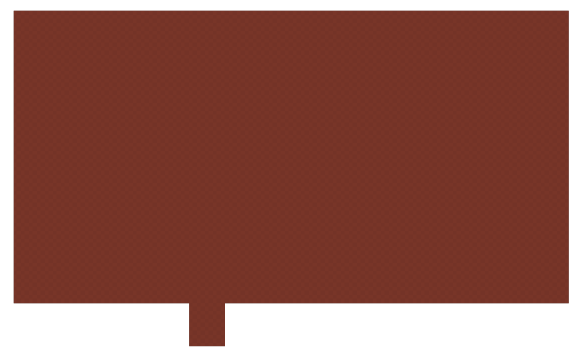

Figure 4: Implementation of micro strip patch antenna in ADS

Figure 4 shows the implementation of rectangular micro strip patch antenna in Agilent ADS software with a size of $38 \times 27 \mathrm{~mm}$. It has FR4 as a substrate material and aluminium as a conducting material in ground over a operating frequency range of $3 \mathrm{GHz}$. We have chosen the substrate material as FR4 since it has low loss and easy to fabricate. The impedance matching is high due to the placement of feeding line on the left edge of the patch. Since rectangular patch is easy to design and have a good polarization characteristic, the antenna parameters such as return loss is highly desirable and insertion loss is minimum. Thus our system has high efficiency.

\section{APPLICATIONS}

Some of the applications of power dividers are TV analyzer, hand-held application, military application, satellite application, antenna arrays, base stations, ratio measurement, wireless applications such as WiMAX, WLAN, Wi-Fi etc.,

\section{SIMULATION RESULTS}

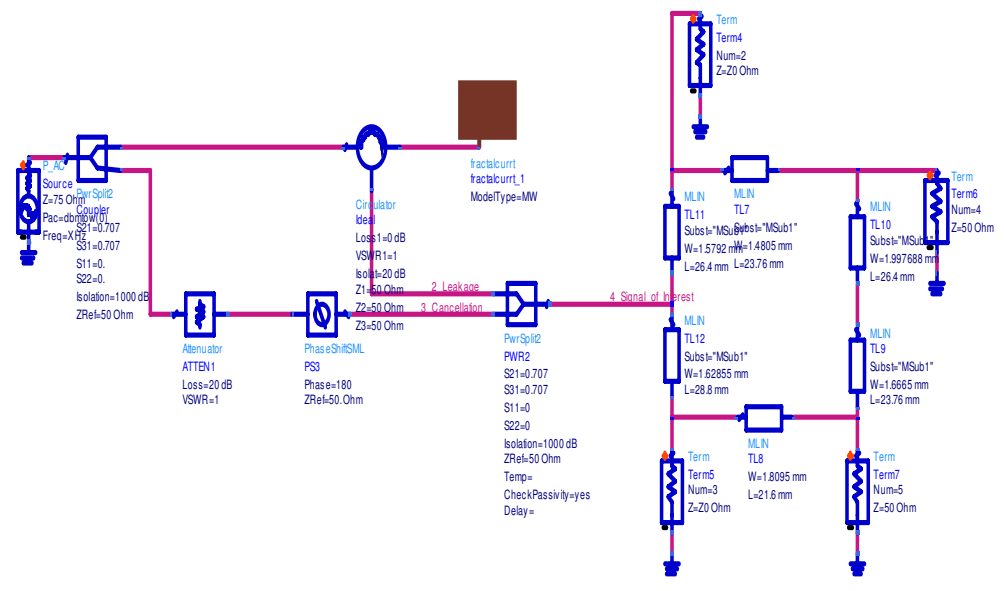

Figure 5: Implementation of proposed system in ADS software

Above figure shows the system implementation in ADS software with the help of RF and microwave tools. The power splitter is used to split the power where as antenna is used to give 
International Journal of Information Sciences and Techniques (IJIST) Vol.2, No.6, November 2012

source to the system and circulator is used to transmit a microwave or radio frequency signal entering any port is transmitted to the next port in rotation (only). This system is operated over a frequency range of $3 \mathrm{GHz}$ with $1.5 \mathrm{GHz}$ as a center frequency. The simulation result of this system is shown below.

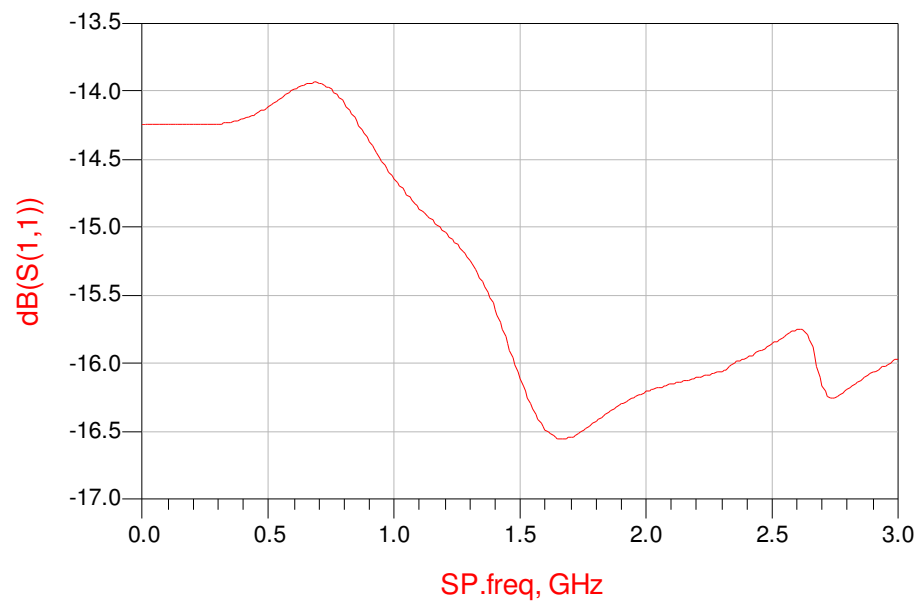

Figure 6: Return loss of the system

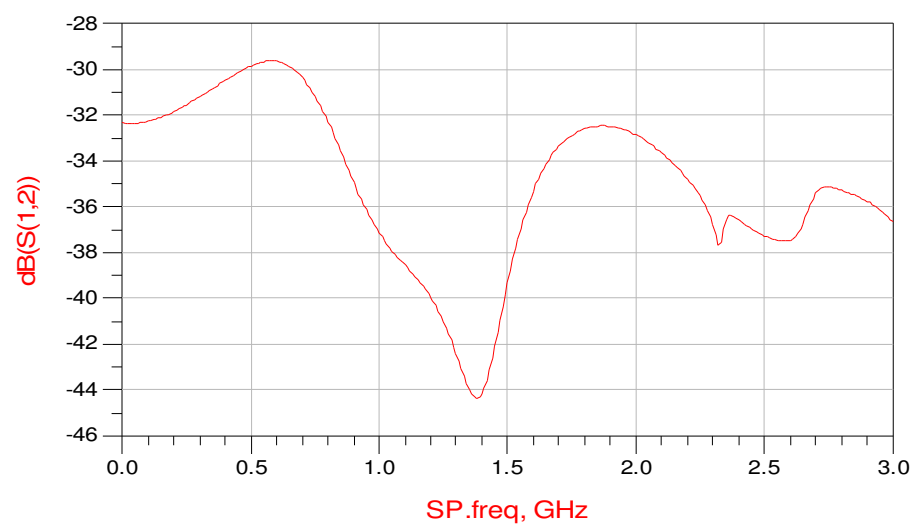

Figure 7: Insertion loss of the system 


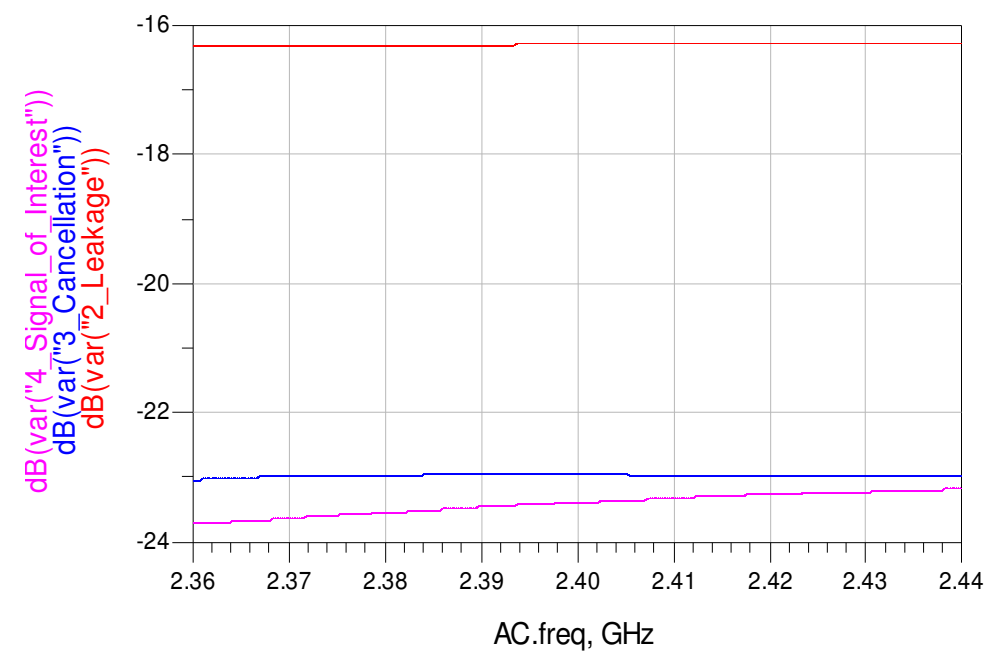

Figure 8: Leakage cancellation of the system

Thus, the system is designed and simulated in good manner with ADS software and the simulation parameters $[1,8,9]$ such as IL, RL and leakage cancellation is analyzed. Figure 6 shows the RL of system which is highly desirable of about $-16.11 \mathrm{~dB}$. Figure 7 shows the IL of system which is about $-39.291 \mathrm{~dB}$. In the system, leakage cancellation is more important to cancel the leakage signal to improve the efficiency of the system. Figure 8 shows the leakage cancellation of the system which is about $6 \mathrm{~dB}$. That is, the leakage signal gets cancelled of about $6 \mathrm{~dB}$.

\section{CONCLUSION}

Thus we conclude that a new modified system for equal power division is designed successfully and the parameters such as RL, IL and leakage cancellation get minimized of about $-16.11 \mathrm{~dB}$, $39.291 \mathrm{~dB}$ and $6 \mathrm{~dB}$ respectively which operate over an operating frequency range of $3 \mathrm{GHz}$ with $1.5 \mathrm{GHz}$ as a center frequency and it is suitable for base stations and antenna arrays. The system is designed using ADS software (2009).

\section{REFERENCES}

[1]. D.M. Pozar, Microwave Engineering, Third Edition, John Wiley \& Sons: New York, 2005.

[2]. Yongle Wu, Yuanan Liu, and Shulan Li "A Modified Gysel Power Divider of Arbitrary Power Ratio and Real Terminated Impedances" “ieee microwave and wireless components letters, vol. 21, no. 11, november 2011 "

[3]. Li, X., S.-X. Gong, L. Yang, and Y.J. Yang, “A novel Wilkinson power divider for dual-band operation" Journal of Electromagnetics Waves and Applications, Vol. 23, Nos. 2-3, 395-404, 2009. 
International Journal of Information Sciences and Techniques (IJIST) Vol.2, No.6, November 2012

[4]. Zhengyu Sun, , Lijun Zhang, Yuepeng Yan, and Hongwen Yang "Design of Unequal Dual-Band Gysel Power Divider With Arbitrary Termination Resistance" ieee transactions on microwave theory and techniques, vol. 59, no. 8, august 2011".

[5]. H.Zhang, X.Shi, F.Wei and L.Xu, Compact wideband Gysel Power Divider with arbitrarypower division based on patch type structure, Progress In Electro magnetics Research, Vol. 119, 395-406, 2011.

[6]. Muhammad Kamran Khattak Osama Siddique Waqar Ahmed, Linnaeus university "Design and Simulation of Microstrip Phase Array Antenna using ADS" 2011.

[7]. zhang, $\mathrm{x}$. shi, f. wei, and 1. $\mathrm{xu}$ " compact wideband gysel power divider with arbitrary power division based on patch type structure "Progress In Electromagnetics Research, Vol. 119, 395406, 2011"

[8]. www.microwaves101.com.

[9]. Annapurna Das,Sisir K Das,"Microwave Engineering”, Tata Mc Graw Hill,2000.

[10]. Ang, Teo Hong "conceptual design and software simulation of A wideband leakage cancellation circuit” Naval Postgraduate School December 2010”.

\section{BIBLIOGRAPHY}

Mrs.S.Banu was born on $26^{\text {th }}$ January 1989 in Tamilnadu, India. She holds a bachelors degree in Electronics and Communication Engineering from Anna University, LCR college of Engineering and Technology,Tiruttani during 2010 and doing masters degree in Wireless Communication Systems in Periyar Maniammai University, Vallam, Thanjavur, TamilNadu. To her credit she has one publication in impact factor journal and four conference proceedings. Her areas of interest are microwave engineering and $\mathrm{RF} /$ Antenna design. Her current research is on RF/Antenna designing. She can be reached on rememberbanu@gmail.com.

Ms.A.Vishwapriya was born on $22^{\text {nd }}$ June 1990 in Tamilnadu, India. She holds a bachelors degree in Electronics and Communication Engineering from Anna University Coimbatore, PGP college of Engineering and Technology, Namakkal, Tamilnadu during 2011 and doing masters degree in Wireless Communication Systems in Periyar Maniammai University, Vallam, Thanjavur, Tamilnadu. To her credit she has one publication in impact factor journal and four conference proceedings. Her areas of interest are communication systems, microwave engineering. Her current research is on RF/Antenna designing. She can vishwaa.nivi@gmail.com.

Ms.R.Yogamathi was born on $2^{\text {nd }}$ August 1990 in Tamilnadu, India. She holds a bachelors degree in Information Technology from Anna University-Trichy, Anjalai Ammal Mahalingam Engineering College during 2011 and doing masters degree in Wireless Communication Systems in Periyar Maniammai University, Thanjavur. To her credit she has one publication in impact factor journal and four conference proceedings. Her areas of interests are OFDM and RF/Antenna design. Her current research is on RF/Antenna designing. She can be reached on yoga.mathi@yahoo.com

Mrs.A.V.Meenakshi was born on $7^{\text {th }}$ June 1977 in Tamilnadu, India. She holds a bachelors degree in Electronics and Communication Engineering from Madras University, Government College of Engineering during 1998, a master's degree in Communication Systems from Anna University, Thiagarajar College of Engineering, Madurai during 2004. She is currently working as an Assistant professor in Periyar Maniammai University, Thanjavur, India. She has more than 10 years of experience in
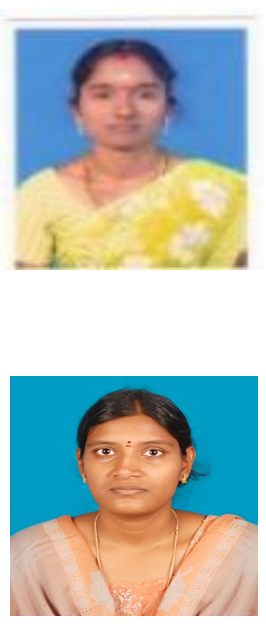

be reached on
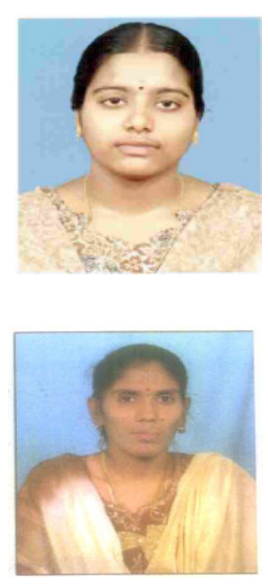
International Journal of Information Sciences and Techniques (IJIST) Vol.2, No.6, November 2012

teaching engineering in Tamilnadu, India. She has also authored or coauthored over 6 international journal papers and 13 international conference papers. Her current research interests and activities are in signal processing, RF components design and wireless communication. She can be reached on meenu_gow@yahoo.com

Dr.SPK.Babu was born on $2^{\text {nd }}$ December 1971 in Tamilnadu, India. He holds a bachelors degree in Electronics and Communication Engineering from Bharathiar University during 1995, a master's degree in Communication Systems from Madurai Kamaraj University during 1998 and PhD from University Sains Malaysia, Penang, Malaysia during 2010. He has more than 13 years of experience in teaching engineering in India and Malaysia. To his credit he has two publications in impact factor journal and few conference proceedings. He is a life member of Indian Society for Technical Education. His research interests include signal processing for digital communication, antenna design and soft computing for communication systems. Mail id: spkbabu@pmu.edu 